\title{
Mathematics and Music in Context: The Contribution of Erasmus Horicius to the Emergence of the Idea of Modern Number
}

\author{
Oscar João Abdounur \\ University of São Paulo, Brazil \\ E-mail: abdounur@gmail.com \\ (Received March 15, 2016; Accepted May 25, 2016)
}

\begin{abstract}
This article covers questions of how the relationship between mathematics and theoretical music throughout western history shaped modern comprehension of critical notions such as "ratio" and "proportion". In order to do that, it will be consider a procedure taken by Erasmus of Höritz, a Bohemian mathematician and music theorist who emerged in the early $16^{\text {th }}$ century as a German humanist very articulate with musical matters. In order to divide the tone, Erasmus preferred to use a numerical method to approach the geometrical mean, although he did not recognize his procedure itself as an approximation of the true real number value of the geometric mean. The Early Modern Period saw the growing use of geometry as an instrument for solving structural problems in theoretical music, a change not independently from those occurred in the conception of ratio/number in the context of theoretical music. In the context of recovery of interest in Greek sources, Erasmus communicated to musical readers an important fruit of such a revival and was likely the first in the Renaissance to apply explicitly Euclidean geometry to solve problems in theoretical music. Although Erasmus also considered the tradition of De institutione musica of Boethius, he was based strongly on Euclid's The Elements, using geometry in his De musica in different ways in order to solve musical problems. It is this comprehensive geometrical work rather than the summary arithmetical and musical books of Boethius that serves Erasmus as his starting-point. However, Erasmus proposed a proportional numerical division of the whole tone interval sounding between strings with length ratio of 9:8, since it was a primary arithmetical problem. This presentation aims at showing the educational potentiality of the implications of such a procedure of Erasmus on the transformation of conception of ratio and on the emergence of the idea of modern number in theoretical music contexts. Under a broader perspective, it aims at show the implications on education of a historical/epistemological and interdisciplinary appraisal of theoretical music and mathematics.
\end{abstract}

Key words: ratio, irrationality, number, mathematics/music interrelationships

\section{Introduction}

Erasmus Horicius was a Bohemian mathematician and music theorist. He was the first in the Renaissance extensively to apply Euclidian geometry to solve problems in music theory. Erasmus went back to the Greek sources of the doctrines of Boethius, communicating to musical readers an important fruit of the revival of interest in ancient texts. University registers show that he has been at Ingolstadt (1484), Erfurt (1486), Cologne (1488, where he received the Magister degree), Kraków (1494), Tübingen (1499) and Vienna (1501). His Musica was written probably between 1504 and 1508, where Horicius used geometry in different ways in order to solve musical problems, applying such a subject for instance to musical intervals. He aimed to emulate the method of the ancient Greeks in applying mathematics to study sensory phenomena, following in particular the method of the ancient Greek Aristoxenus of Tarent, a disciple of Aristotle, in applying geometry to music.

Although Erasmus also considered the tradition of De institutione musica of Boethius, he was based strongly on Euclid's The Elements, using geometry in his De musica in different ways in order to solve musical problems. It is this comprehensive geometrical work rather than the summary arithmetical and musical books of Boethius that serves Erasmus as his starting-point. However, Erasmus proposed a proportional numerical division of the whole tone interval 
International Journal of Mathematical, Engineering and Management Sciences

Vol. 1, No. 2, 62-67, 2016

https://dx.doi.org/10.33889/IJMEMS.2016.1.2-007

sounding between strings with length ratio of 9:8, since it was a primary arithmetical problem. This article tries also to shows the educational potentiality of the implications of such a procedure of Erasmus on the transformation of conception of ratio and on the emergence of the idea of modern number in theoretical music contexts. Under an educational perspective, it aims at show the implications on education of a historical/epistemological and interdisciplinary appraisal of theoretical music and mathematics.

In order to do that, it will be considered here a passage in chapter seventeenth of Book VI of Erasmus De musica, entitled "Propositio decimaseptima Toni proportionem scilicet sesquioctavam in duas proportiones equales artificialiter et geometrice dividere ". It concerns the equal and proportional numerical division of the whole tone interval sounding between strings with length ratio of 9:8, a problem which confused the musical theorists from Antiquity up the Renaissance and that played an important part in the historical process that led to the emergence of equal temperament. In this passage Erasmus seemed to be in a position to solve such a problem.

\section{Division of the tone}

The problem of the division of the tone arose from the Pythagorean discovery of numerical indivisibility of a superparticular or epimoric ratio, i.e., $n: n+1$, by its geometrical mean, in particular applicable to the division of the ratio 9:8. Given $p<x<q$, where $p$ and $q$ are integers and the ratio $p: q$ is superparticular, $x$ cannot be both an integer and at the same time fulfill the condition $p: x=x: q$, that is, be the geometric mean of $p$ and $q$. From the musical point of view, the harmonical meaning of the geometric mean would result in the division of the tone in 2 exactly musical intervals, which is possible for instance with the equal temperament. Nevertheless, mathematically, the equal division of the tone 8:9 provides ratios involving surds or incommensurable ratios underlying musical intervals and such a procedure were considered impossible by Pythagoreans in theoretical music, since these intervals could be determined only by ratios of integer numbers.

Attempts to divide the tone were already done, however, since Antiquity by Aristoxenus (fourth century B.C.), who conceived the theoretical nature of music as essentially geometric, understanding pitches, musical intervals and also distances as continuous quantities that should follow the rules of the Euclidean geometry and should be capable of being divided continuously, which inevitably raises questions concerning the nature of ratio in this context. Traditionally it is considered that Aristoxenian music theory rejected the position of the Pythagoreans in the sense that musical intervals should properly be expressed only as mathematical ratios involving whole numbers, asserting instead that the ear was the sole guide for musical phenomena (WinningtonIngram, 1995, 592). It did not mean however that Aristoxenus' theory could not be put on a mathematical base related to the developments in Greek mathematics of his time. Aristoxenus preferred geometry to arithmetic in solving problems involving relations between musical pitches and believed in the possibility of dividing the tone into two equal parts, conceiving musical intervals and ratios as continuous magnitudes.

Such an idea unchained many reactions expressed for instance in the Sectio Canonis (Barbera, 1991, 125) ascribed to Euclid and much later in the De institutione musica (Bower and Palisca,

\footnotetext{
${ }^{1}$ Proposition decimaseptima how to divide the sesquioctave ratio (that is, 9:8) of the whole tone into two equal ratios, artificially and geometrically.
} 
International Journal of Mathematical, Engineering and Management Sciences

Vol. 1, No. 2, 62-67, 2016

https://dx.doi.org/10.33889/IJMEMS.2016.1.2-007

1989, 88) of Boethius in the early Middle Ages, which stood for a strong Pythagorean tradition in theoretical music in the Middle Ages. Following the Pythagorean tradition, many medieval musical theorists maintained the impossibility of the equal division of the tone, which would mathematically lead to incommensurable ratios underlying musical intervals. Such a position begins to change in the 15th century and was eventually systematically overcome in the early Renaissance through scholars like Nicholas of Cusa, Erasmus of Höritz, Faber Stapulensis, Henricus Grammateus, Pedro Ciruelo, Juan Bermudo and others, who proposed the equal division of tone mostly by means of geometry. In his Musica, Erasmus of Höritz made use of an abstract numerical procedure to propose a solution for the problem of the equal division of the tone, expressing rather as a number the geometrical mean between the terms of the ratio 9:8 underlying the tone

\section{The De Musica Speculativa from Erasmus Horicius}

Erasmus' De musica emerged in a time when the rediscovery, translation and publication of sources from Antiquity, such as the works of Euclid, Archimedes and Ptolemy, increased interest and development on number theory. Gaps in the Pythagorean numerical system was quite disturbing resulting in crisis and conceptual changes in the demarcation of the disciplines arithmetic and geometry. So ratios involving surds, i.e., incommensurable quantities, could only be discussed in the domain of continuous quantity and would request the unification of such two disciplines as well as the conquest of a number continuum on mathematical activity.

Particularly for Erasmus, Arabic and Hindu concepts were highly influential, since they promoted the development of Greek mathematics and handled entities such as negative and irrational numbers, as well as allowed, with the introduction of Hindu numerals by Fibonacci, the computation of unprecedented complexity as well as the development of extremely large numbers, being the latter an important component in Erasmus' division of the whole tone ratio, as it will be seen in the following.

In the Chapter Seventeenth of Book VI, Erasmus refers specifically to the division of the 9:8 ratio, which represents the musical interval of a whole tone. In the 4 previous chapters of book VI, Erasmus demonstrated incompletely the divisibility of other superparticular ratios into equal and proportional halves, like the octave (2:1), fourth (4:3), fifth (3:2) and minor third (6:5).

In Chapter Seventeenth, Erasmus proposed an abstract numerical procedure to find the geometrical mean between the terms of ratio 9:8 underlying the tone, expressing it as a number. He did not use the geometrical construction of mean proportional to two given straight lines from proposition 13 of Book VI of Euclid, as did for instance Jacques Lefèvre d'Etaples in 1496, using exclusively non-numerical Euclids methods capable of being carried out with straightedge and compass, according to the Fig.1.

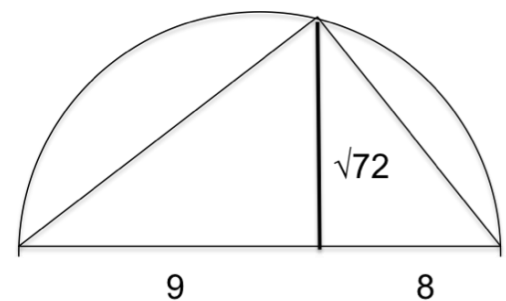

Fig. 1. Proposition 13 of book VI of Euclid 
International Journal of Mathematical, Engineering and Management Sciences

Vol. 1, No. 2, 62-67, 2016

https://dx.doi.org/10.33889/IJMEMS.2016.1.2-007

He attempted rather to reach an expression for the ratio for the supposedly equally proportional halves of the whole tone interval using very large integer numbers. He did it first using proposition 15 of Book $\mathrm{V}$ of the Elements, which asserts, that $a: b:: a m: b m$. Following his method, the half of the 9:8 ratio of a tone could be obtained by the geometric mean of its expansion into the term 34828517376: 30958682112 . This ratio was derived directly from 9:8 by multiplying numerator and denominator by the factor 3869835264 , a procedure guaranteed by proposition 15 of Book V for $a=9, b=8$ and $m=3869835264$. The proportionality between the original ratio 9:8 and 34828517376:30958682112 allows a mapping between intermediate terms of the ratio 9:8, including the mean; and numbers between the terms of its expansion into a large number ratio, considering that the interval determined by the expansion is much more sub divisible and that the greater the distance between the terms in the large number ratio, the greater the precision one can get for the intermediate terms of the ratio 9:8, represented by the large number between the two terms of the large number ratio. Since there were not decimal fractions at this time, the proportional extended ratio is used for the purpose of extracting the square root with a high degree of precision, in this case associated with large integer numbers rather than with places after the decimal point. The bigger the distance between the terms in the large number ratio, the better the precision in which the geometrical mean is obtained. Nevertheless Erasmus seemed not to worry carrying out any computation in the text and he did not present his result as an approximation of the true real number. He is the first author to propose an abstract numerical procedure for the given problem, expressing it as a number and avoiding using the construction of a geometrical line. Since it was a primary arithmetical problem, it could be solved "artificialiter", that is, numerically.

Erasmus asserts that “... in musical demonstrations we are forced to use all kinds of ratios ....since not all shapes of consonances and also dissonances are founded in rational ratios and for that reason we must not neglect the ratios of surds..." (Erasmus Horicius, ca. 1500, fo. 61v). Erasmus considered here incommensurable ratios or irrational numbers in musical contexts. For music theoretical purposes, it would seem in principle that in order to make use of Eudoxus' theory of book V of Euclid's Elements on which theory of ratios of surds is based and which deals with abstract quantities with continuous nature; he established a link between continuous and discrete quantity ${ }^{2}$. Erasmus realized that the sought for a geometrical mean to the ratio underlying the whole tone could not result in a rational number and instead of changing the domain at this point from discrete quantity of numbers to continuous quantity of geometrical lines, he establish a link between continuous and discrete quantity, proposing

\footnotetext{
${ }^{2}$ It is possible to identify similar ideas between the numerical division of the tone proposed by Erasmus and the Eudoxus' definition V of Book 5 of the Elements. Whereas Erasmus confined a searched irrational number by using only integers, Eudoxus' definition corresponded, arithmetically speaking, to establish a proportionality of ratios through the confinement of ratios with integer terms. In these analogous procedures, Erasmus and Eudoxus got precision, to find an irrational number and to establish a proportionality between two given ratios, respectively, through ratios with big terms. Erasmus made use of "The Elements", nevertheless his source was the Campanus' translation, which had an arithmetical terminology that was not derived from the geometrical ratio theory of Book V of Euclid, but instead from a number of different sources including very likely the Arithmetic of Jordanus de Nemore from $13^{\text {th }}$ century. Such a fact makes, on the one hand, not plausible that Erasmus would have had access to Eudoxus definition in the original sense and, on the other hand, very instigating the strong and curious structural analogy between both procedures.
} 
International Journal of Mathematical, Engineering and Management Sciences

Vol. 1, No. 2, 62-67, 2016

https://dx.doi.org/10.33889/IJMEMS.2016.1.2-007

a number continuum, although not explicitly, creating a very dense discrete point space between the original terms 9 and 8 by their expansion.

\section{Concluding Remarks}

It is thinkable that if Erasmus really thought that he could divide the sesquioctave ratio in terms of a purely numerical operation, he must have possessed an at least rudimentary concept of the number continuum. Such an assumption is corroborated by a passage appearing later on in Chapter 17, where he seems to refer directly to the idea of such a continuum, mentioning Boethius as a prisoner of the Pythagorean doctrine of discrete integer number not accessing all ratios of numbers (Erasmus Horicius, ca. 1500, fo. 67v). Just before this passage, Erasmus asserts that the exact half of the whole tone interval would be provided by extracting the square root of the product of its terms 8 and 9, which would be sqrt (72) (Erasmus Horicius, ca. 1500, fo. 67v). He did not however relate explicitly this result with the computations he presented. He got the large number ratio, but it was still needed to find the geometrical mean between the two terms. Since he presented the way to do this by extracting square roots of 9.8 , one might ask why he did not do it from the ratio 9:8, or if he produced the proportional large number ratio, how could he use this representation to the extraction mentioned above and/or to approach the geometrical mean. It might be assumed that he left it to the reader. Such a method is structurally analogous to that used by Eudoxus to establish a criterion to compare ratios including incommensurable ones. In such an analogy, it is especially interesting and maybe the attribute which make this analogy structurally strong is that both procedures made use only of commensurable ratios in geometric and arithmetic contexts. This feature has educational potential, being an example of using history for epistemological purpose in the learning/teaching dynamics. Both procedures established by Eudoxus and Erasmus use only commensurable/rational ratios/numbers to introduce incommensurable/irrational ones, with a geometrical approach and an arithmetical one respectively and exemplify ways for introducing irrational numbers making use only of integers. Such historical analogous examples also allows to introduce a broader sense for the crisis of incommensurable, now presenting it in parallel to its musical version, in which Erasmus created a criterion to deal with such magnitudes making use only of commensurable ones as Eudoxus did.

Theoretically based on many geometrical propositions and, unusually, modeled on Euclidean style, Musica dealt with ratio as a continuous quantity, announcing perhaps what would emerge as an arithmetical treatment of ratios in theoretical music contexts during the sixteenth century, approaching ratio to a real number. Under an educational perspective, such two historical approaches for theories of ratio make music a favorable context for the differentiation between ratios, fractions and numbers, insofar as the semantic distinction between such two approaches stands out in this context. In music contexts, two musical intervals produced by two proportional ratios are clearly different although similar, whilst such a difference disappears in an arithmetical context, in which these ratios are identified with numbers. For instance, the ratios 2:3 and 4:6 produce musically two fifths with an octave difference. They are proportional, similar by not the same, noticeably not the same, whereas the difference between such ratios disappears in an arithmetical context, since $2 / 3$ is equal to $4 / 6$ arithmetically speaking. Interestingly, Erasmus could have easily solved the equal division of the tone making use of the proposition of Euclid's Elements which provide the geometrical mean as the height of a right angled triangle. Nevertheless, missing the concept of infinity, he preferred to use a numerical method to approach such a mean, although his procedure did not recognize itself as an approximation of the true real number value of the geometric mean. Erasmus provided a mathematical theoretical structure for a 
International Journal of Mathematical, Engineering and Management Sciences

Vol. 1, No. 2, 62-67, 2016

https://dx.doi.org/10.33889/IJMEMS.2016.1.2-007

virtual pitch relation space, a continuum of rational numbers, that can be seen as an important step for laying the foundations for the real number system.

\section{References}

Barbera, A. (1991). The Euclidean Division of the Canon. Lincoln: Univ. Nebraska Press.

Bower, C. M. and Palisca, C. V. eds. (1989). Fundamentals of music. anicius manlius severinus Boethius. New Haven \& London: Yale University Press.

Erasmus Horitius. 1500 "De Musica" [ca. 1500], Reg. Lat. 1245, Biblioteca Apostolica Vaticana

Palisca, C. V. (1994) "The Musica of Erasmus of Höritz," C. Palisca, Studies in the History of Italian Music and Music Theory. Oxford: Clarendon Press, pp. 146-67.

Rommevaux, S., Vendrix, P., Zara, V. (2011). Proportions: science, musique, peinture \& architecture. Collection - études Renaissantes. Brepols: Turnhout.

Winnington-Ingram, R. P. (1995). "Aristonexus" In: The new Grove dictionary of music and musicians, edited by Stanley Sadie, 592. London: Macmillan. 